\title{
The Construction and Application of the In-class Flipped Teaching Model Based on Micro-classes in Junior High School Information Technology Courses
}

\author{
Xinfei Qing, Min Tian*, Jie Zhou \\ Shihezi University, Shihezi 832000, Xinjiang, China. \\ E-mail: 94662061@qq.com \\ Project: Shihezi University Postgraduate Course Teaching Reform Project (2019Y-JGFF03)
}

Abstract: the in-class flipped teaching model concentrates the teaching links of flipped class in the classroom, and completes the process of knowledge construction to internalization in class. This restructuring of teaching structure is more in line with the current education situation in China, but compared with the flipped classroom, China has less theoretical research and practical exploration of the flipped teaching model in class. Therefore, through the research on the current situation of flipped classroom teaching models at home and abroad, combined with the characteristics of junior high school information technology courses, a micro-class-based in-class flipped teaching model was constructed and implemented in junior high school information technology courses. The survey results were obtained to assist related theories and practical exploration.

Keywords: Flipping in Class; Teaching Model; Junior High School Information Technology; Micro-class

\section{Introduction}

Education informatization has received widespread attention from the society in recent years, especially under the special circumstances of "stopping work without stopping school" during the epidemic in early 2020, which highlights the important role of education informatization. Therefore, it is of practical significance to effectively promote the deep integration of information technology and education informatization ${ }^{[1]}$.

The flipped classroom, as one of the many new models that are highly respected, has triggered an upsurge of teachers' exploration and practice since it was introduced into China. This model takes students as the center, fully cultivates students' autonomous learning ability, and promotes the reform and innovation of teaching structure ${ }^{[2]}$. However, after studying the literature results and experience summaries of frontline teachers, it is not difficult to find that there are certain local disconnections after the introduction of flipped classrooms in China, especially in the education and teaching of different disciplines and regions ${ }^{[3]}$.

Combined with the practical application of flipped classroom in the course of junior high school information technology, first of all, it has higher requirements for students' learning environment. Every student needs to be equipped with a computer and be in a smooth network environment, which is difficult for many boarding students in middle schools. Secondly, it is difficult to guarantee whether the learning effect can meet expectations in the face of high pressure to enter a higher school and heavy academic burden.

According to the above problems, the model of "in-class flipped teaching" based on micro-classes is proposed. Focusing the teaching links of flipped class in the classroom, the self-learning learning background of knowledge is completed in class, and the model of self-learning new knowledge through teaching videos, courseware and other teaching resources after class will increase the extracurricular burden of middle school students, and it will affect this age group. Students' learning consciousness is undoubtedly a challenge, from learning, discussion and answering to internalization and improvement. According to the characteristics of information technology courses, the main teaching resource of micro-classes is integrated into the in-class flipped teaching model to improve the teaching effect of junior high school information technology courses in the current situation, and to explore and practice new models suitable for localized teaching.

Copyright (C) 2020 Xinfei Qing et al

doi: 10.18282/le.v9i6.1292

This is an open-access article distributed under the terms of the Creative Commons Attribution Non-Commercial License

(http://creativecommons.org/licenses/by-nc/4.0/), which permits unrestricted non-commercial use, distribution, and reproduction in any medium, provided the original work is properly cited. 


\section{The construction of the in-class flipped teaching model based on micro-classes}

The smooth construction and implementation of the new teaching model require the support of many factors. First, the support of the teaching environment. Generally, schools are equipped with corresponding microcomputer classrooms for information technology courses. One computer per person can meet the requirements for students to learn micro-courses, courseware and other related materials in the self-learning process. Therefore, this model does not require high school software and hardware equipment, and is relatively convenient to promote.

Second, it conforms to the characteristics of learners' psychological development. For junior high school students, the abstract logical thinking began to replace concrete thinking. Their independent thinking develops rapidly and they are eager to think independently to solve problems, and have a critical thinking consciousness, and dare to express personal opinions. This period is a critical period for stimulating students to explore new knowledge, discover problems, and cultivate students' ability to learn independently. However, due to the poor self-control ability of students at this age and the weak resistance to temptation, they cannot arrange their study time reasonably. This model is student-centered, with learning and teaching, allowing students to discover problems, think independently, and try to solve them in autonomous learning. Micro-class learning helps cultivate students' complex thinking and promote deep learning. Questions and answers will be discussed in class, and exercises will be consolidated. After class, students' works will be displayed and evaluated, and the class summary will be made. The whole learning process is in line with the students' cognition and attention characteristics. All learning links are completed in the classroom, and students are guided, urged, and answered by teachers while studying independently. The benign interaction between teachers and students will undoubtedly help enhance the learning effect.

Third, it conforms to the characteristics of information technology courses. Compared with other courses, the information technology course pays more attention to the operation and practical ability of students. Traditional classroom teachers explain to the students while operating, or the teacher demonstrates the mode where the students start to operate on the computer. There are some students who can't keep up with the teacher's explanation rhythm, or the teacher has forgotten to complete the operation task after explaining the students, and it is difficult to have time to reflect, digest problems, or apply the new model proposed. In this case, students can adjust the viewing progress according to their own acceptance ability by watching the micro-classes to learn the operational tasks of this lesson, and they can watch repeatedly if they encounter problems during the operation. The quality of students' learning has been improved, and more ample time is left for students to operate and practice, so as to better realize the internalization and absorption of knowledge.

Based on the feasibility analysis of the above three points, the new model was constructed. The core of the model is the "three links in class", which means that a class is divided into questions-solving links before the class, questions and answers during the class, and the final class summary after the class. In order to make the model more systematic and complete, the pre-class curriculum development and after-class summary and reflection links have been added. The following figure shows the model of the construction.

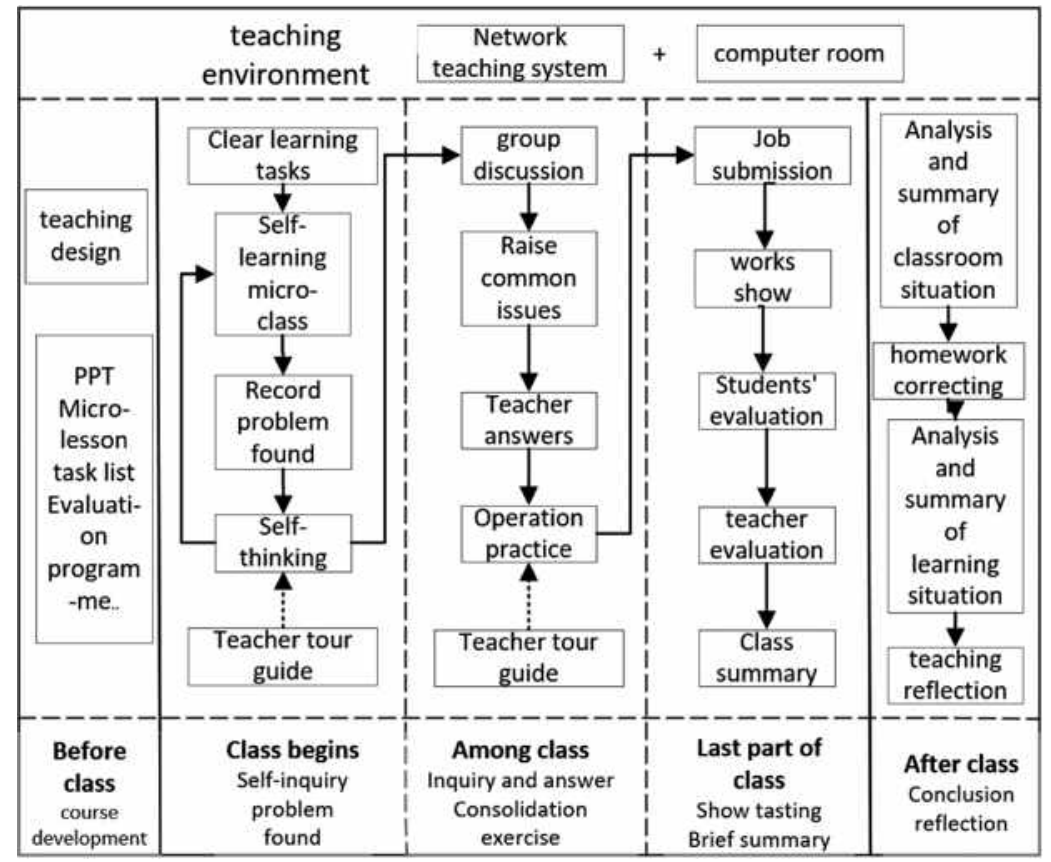

Figure 1. Model diagram of the in-class flpped teaching model based on micro-classes. 
The in-class flipped teaching model is not only a flip of teaching structure, but also a flip of knowledge teaching and internalization, and a flip of the roles of teachers and students. The focus of this model has changed from teacher's teaching to student's learning, that is, to guide students to learn autonomous learning. It allows students to construct a knowledge system autonomously under the guidance of micro-class resources, use the visual characteristics of micro-class resources to understand knowledge deeply, and learn to treat problems dialectically and solve problems autonomously in the discussion and operation exercises, so as to gradually reach the level of thinking. Deep learning.

\section{Summary and reflection on curriculum practice}

In order to verify the effect of the implementation of this model, one semester of curriculum practice was conducted in the first grade. After the practice, in order to understand the experience and results of the new in-class flipped teaching model supported by micro-classes, a simple interview and questionnaire survey were conducted with a total of 60 students in the experimental class. The investigation is mainly carried out from several aspects such as students' interest in curriculum learning, degree of individualized learning, learning autonomy, degree of cooperative learning between teachers and students and students, and practical operation ability.

It can be seen from the survey results that the implementation of the new model has increased the interest of most students in the course of information technology. The integration of the main teaching resource in the new mode of micro-courses has attracted students' interest in learning, and students can control their learning progress independently, gain a sense of accomplishment and personalized learning experience from learning, and enhance their independent learning ability. Secondly, micro-classes are suitable for information technology courses with strong operability, leaving students to increase the time for operation and practice, and they can watch videos repeatedly when encountering problems in operation, so that students' learning efficiency and practical operation ability will be improved. Most students also enjoy the discussion and answering session and the teacher's individual counseling increased the interaction between teachers and students, and they like cooperative learning. Analyzing the quality of students' homework and survey results, it is found that under this model of learning, most students have a relatively high level of knowledge, and their learning has changed from mechanical memory to deep learning.

Of course, there are also a small number of students whose interest in learning has not been improved, and the level of knowledge mastery has not yet reached the requirements. Through observation in the classroom and communication with students, it can be found that these students have poor self-control and are accustomed to the traditional way of teaching. They like to do things that have nothing to do with learning when being asked to learn independently and discuss problems. The disconnection of early knowledge leads to a lack of interest in later learning, so the learning effect is not ideal. For these students, teachers should pay more attention to them, remind them in time, and guide each student to actively participate in group discussions to avoid grade differentiation. When the class size is large, an assistant can be hired to assist in teaching.

\section{Conclusion}

Through combing the existing flipped classroom teaching model and the feasibility analysis of the current teaching environment, the characteristics of learner's psychological development and the characteristics of information technology courses, this paper constructs a flipped teaching model in class based on micro-classes to realize the specific implementation of the lesson. According to the feedback of the course practice results, it can be seen that the application of this model has improved students' learning interest, learning effect, independent learning ability, practical operation ability and other information literacy. The implementation of the new model should be more in line with academic conditions and closer to the classroom. The actual teaching needs to be further summarized and improved in practical exploration.

\section{References}

1. Guo L. Higher vocational classroom: New thoughts on "flip classes" supported by the Internet. China Vocational and Technical Education 2019; (17): 45-49.

2. Yu H. Exploring the teaching method with the help of micro-class flipped classroom_—Comment on "flipped classroom and micro-curriculum teaching method". China University Science and Technology 2019; (11): 106.

3. Yang Q. Research and application of the "in-class flipped" teaching model based on micro-classes [dissertation]. Shaanxi Normal University; 2017. 